University of Nebraska - Lincoln

DigitalCommons@University of Nebraska - Lincoln

Faculty Publications - Textiles, Merchandising and Fashion Design

Textiles, Merchandising and Fashion Design,

Department of

April 2003

\title{
Characteristics of fading of wool cloth dyed with selected natural dyestuffs on the basis of solar radiant energy
}

\author{
Kunio Yoshizumi \\ Kyoritsu Women's University, Tokyo \\ Patricia Cox Crews \\ University of Nebraska-Lincoln, pcrews@unl.edu
}

Follow this and additional works at: https://digitalcommons.unl.edu/textiles_facpub

Part of the Art and Design Commons

Yoshizumi, Kunio and Crews, Patricia Cox, "Characteristics of fading of wool cloth dyed with selected natural dyestuffs on the basis of solar radiant energy" (2003). Faculty Publications - Textiles,

Merchandising and Fashion Design. 6.

https://digitalcommons.unl.edu/textiles_facpub/6

This Article is brought to you for free and open access by the Textiles, Merchandising and Fashion Design, Department of at DigitalCommons@University of Nebraska - Lincoln. It has been accepted for inclusion in Faculty Publications - Textiles, Merchandising and Fashion Design by an authorized administrator of DigitalCommons@University of Nebraska - Lincoln. 
.Article published in Dyes and Pigments 58 (2003), 197-204. (C) 2003 Elsevier Ltd. All rights reserved.

Posted by permission.

Dyes and Pigments home page > http://www.sciencedirect.com/science/journal/01437208

doi: $10.1016 / \mathrm{S} 0143-7208(03) 00065-2$

\title{
Characteristics of fading of wool cloth dyed with selected natural dyestuffs on the basis of solar radiant energy
}

\author{
Kunio Yoshizumi, Department of Textile Science, Faculty of Home Economics, Kyoritsu Women's University, \\ Tokyo, Japan \\ Patricia Cox Crews, Department of Textiles, Clothing and Design, University of Nebraska-Lincoln
}

Corresponding author K. Yoshizumi: yosizumi@sl.kyoritsu-wu.ac.jp Tel./Fax: + 81-3-3237-2479.

Article submitted May 2002, revised January 2003, accepted April 2003.

\begin{abstract}
Photodegradation characteristics of selected natural dyestuffs were investigated on the basis of solar radiant energy. UVA and UVB fluorescent lamps were also applied to examine wavelength dependencies on the fading characteristics. The natural dyestuffs were observed to have poorer lightfastness in the comparison with AATCC Blue Wool L2. The order of fading susceptibility to solar radiation is as follows: Turmeric $>$ Weld $>$ Madder $>$ L2. Moreover, it was concluded that the natural dyestuffs were strongly sensitive to visible light as well as to UV rays and L2 would be faded by visible light to a small extent. These results provide an important key to understanding the poor lightfastness of some natural dyestuffs.
\end{abstract}

Keywords: Lightfastness; Turmeric; Weld; Madder; AATCC Blue Wool L2; Solar radiation

\section{Introduction}

Fading of dyestuffs by light radiation is one of the most important factors influencing the useful wear life of clothing. Moreover, fading is a major concern to museum personnel who are responsible for preserving textiles from artifacts for future generations to enjoy and study. Textiles colored with some natural dyes remain among the most light sensitive of museum objects and, therefore, pose some of the greatest challenges to long term conservation [1-6].

Lightfastness has been investigated widely and intensively in developing new dyestuffs [712]. Most of fading experiments were made under accelerated conditions with artificial light sources such as carbon arc lamp, xenon arc lamp and so on instead of solar radiation. However, basically, the knowledge of lightfastness characteristics of dyed cloth under the sun is very important to understand the nature of fading. Moreover, radiant energy was not directly measured in many cases whereas lightfastness standards such as Blue Wool Light Fastness Standards of AATCC, and Blue Scales of the Japan Industrial Standard were used as measure of accumulated light intensity. Sometimes, clock hours were just shown as an index of exposure condition [12]. 
Ultraviolet radiation is known to strongly influence fading of natural and synthetic dyestuffs, and visible light has also been shown to contribute to fading to a lesser extent [3,5-7]. However, only limited information exists regarding the effect of wavelength on the fading of natural dyes. A few scientists have examined the effectiveness of UV filters in reducing fading $[5,6]$; others have examined the influence of UV radiation in the photodegradation of disperse dye $[10,11]$ and photoyellowing of wool $[13,14]$.

In this research, characteristics of fading of wool cloth dyed with selected natural dyestuffs were investigated on radiant energy bases by exposure to sunlight outdoors, as well as indoors using artificial light sources emitting UVA and UVB radiation, respectively. The accumulated respective radiant energies were simultaneously measured. In this way, the comparative effects .of wavelength derived from the different types of radiation could be examined.

\section{Experimental}

\subsection{Material and dyeing procedure}

Worsted wool flannel, Style 523, of Testfabrics, Inc. (Middlesex, New Jersey) was scoured and dyed with madder, weld and turmeric. The wool samples were mordanted with alum before dyeing. These dyes were widely used in American and European textiles until synthetic dyestuffs were developed in the nineteenth century. The nineteenth century dyeing procedure was followed to prepare these dyed materials [15]. The specimens were same ones as used previously in Crews' studies [5,6].

AA TCC Blue Wool Lightfastness Standard L2, a reference fabric dyed with a synthetic blue dye known to be quite fugitive to light was also included in the experiment because it is known to be sensitive to UV radiation, but influenced little by visible radiation $[5,6]$.

\subsection{Exposure to light sources}

Dyed specimens were exposed to sun light on the roof of Fourth Hall of Kyoritsu Women's
University in Tokyo, Japan, on sunny and cloudy days, excluding rainy days, during 8 days in August 2001. The specimens were set at a vertical position. Simultaneously, the intensity of sun light was measured using model MS210A UVA (315-400 nm) monitor made by Eiko Co. Ltd and model MS-210W UVB (280-315 $\mathrm{nm})$ monitor made by Eiko Co. Ltd. Photo sensors were equipped with these monitors to measure respective band energies of UVA and UVB. The irradiance was monitored in intervals of 10 sand data accumulated every $10 \mathrm{~min}$.

The specimens were also exposed to artificial lights in the laboratory. UVA fluorescent lamp made by Toshiba Electric Co. Ltd. was used to irradiate specimens with UVA selectively; UVA spectrum is shown in Fig. 1. Similarly, UVB fluorescent lamp made by Toshiba Electric Co. Ltd was used to irradiate specimens with UVB selectively; UVB spectrum is shown in Fig. 2. The UVA and UVB radiant energies were monitored by hand-held instruments, models MS-330A andMS-330B made by Eiko Co. Ltd, respectively.

\subsection{Evaluation of fading}

Color change of the specimens was measured using a Minolta Model CR-200 color analyzer with $1 \mathrm{~cm}$ diameter viewing aperture. Amount of

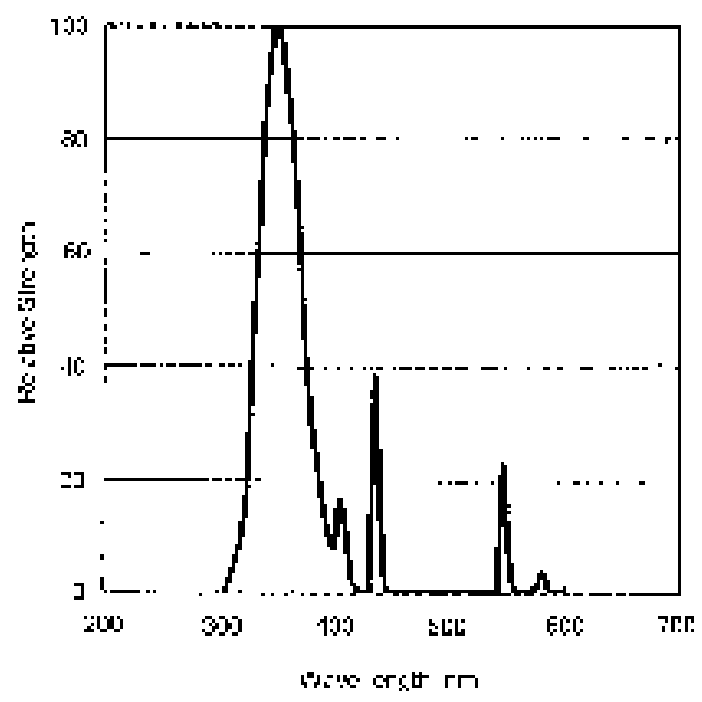

Fig. 1. Spectrum of UVA fluorescent lamp radiation. 


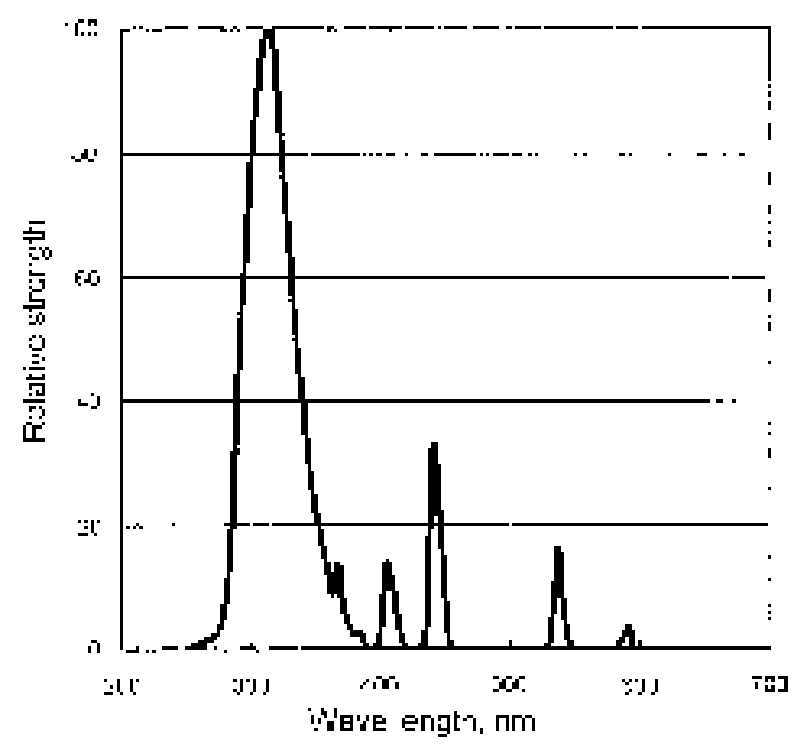

Fig. 2. Spectrum of UVB fluorescent lamp radiation.

fading was evaluated in terms of color difference calculated using the following formula of CIE Committee in 1976:

$\Delta \mathrm{E}=\left[\left(\Delta \mathrm{L}^{*}\right)^{2}+\left(\Delta \mathrm{a}^{*}\right)^{2}+\left(\Delta \mathrm{b}^{*}\right)^{2}\right]^{1 / 2}$

where: $\Delta \mathrm{L}^{*}=$ lightness-darkness difference; and $\Delta \mathrm{a}^{*}=$ redness-greenness difference; and $\Delta \mathrm{b}^{*}=$ yellowness-blueness difference.

\section{Results and discussion}

\subsection{Characteristics of solar irradiation}

Fig. 3 shows the characteristics of UV radiation in Tokyo, Japan, in August 2001. Data involves measurement of diurnal variations recorded every $10 \mathrm{~min}$ from early in the morning until late in the evening. The upper part of the figure shows the variation of UVA irradiation. It is observed that UVA intensity began to increase starting at sunrise (about 04:00 clock) and continued increasing according to the altitude of sun position until a maximum value of about $50 \mathrm{~W}$ $/ \mathrm{m} 2$ was reached at around noon. In the afternoon, the intensity gradually decreased until sunset in an almost symmetrical behavior opposite to the morning.

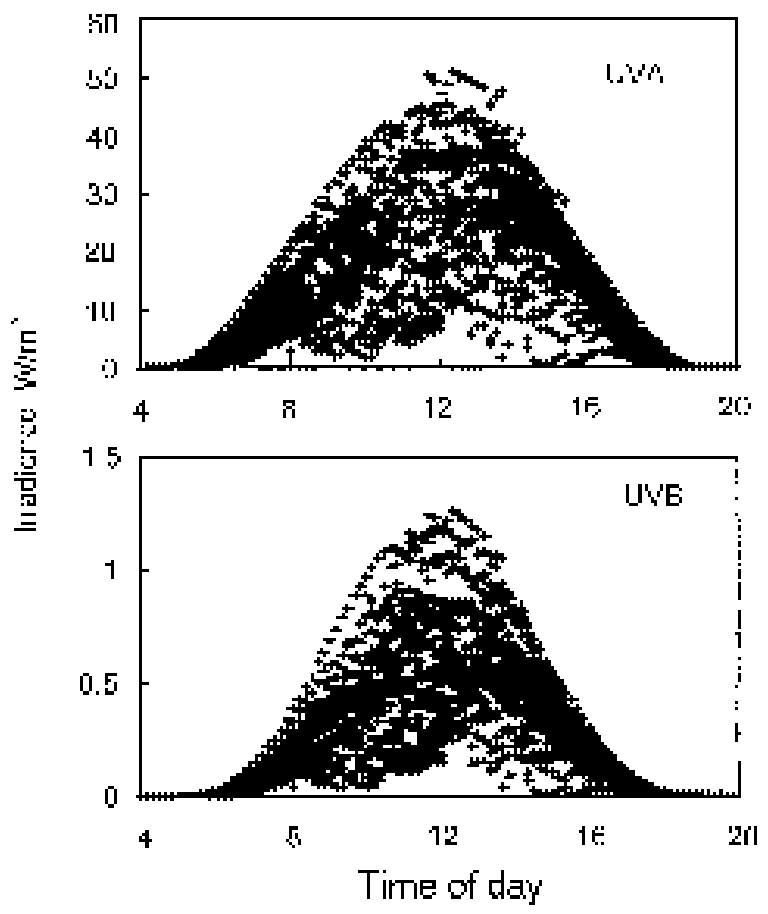

Fig. 3. Diurnal variations of solar UVA and UVB radiation in Tokyo, Japan in August 2001.

Many diurnal variations were observed around noon each day at the periods of maximum solar intensity. These variations are attributed to the absorption and scattering of UVA caused by clouds, rainwater, and gaseous and particulate pollutants in the atmosphere. Moreover, only a few diurnal variations were found at the base line. This means that UVA could reach the surface of the earth to some extent even under rainy conditions.

The lower part of Fig. 3 shows the diurnal variations in UVB radiation which was monitored simultaneously with UVA radiation, described earlier. The UVB irradiance was observed to be very low between 05:00 and 06:00 in the morning and 17:00-18:00 in the evening compared with UVA, both times when the altitude of the sun is lower in the sky. This is considered to be due to that the wavelength of UVB would be more absorbed in the atmosphere than UVA. The maximum irradiance value of UVB is observed to be about $1.3 \mathrm{~W} / \mathrm{m}^{2}$ at around noon. It is noticeable that UVB energy is smaller by a factor of about one fortieth compared with UVA energy. Diurnal variation of UVB was characterized by a steeper bell 
curve in the time sequential pattern compared with UVA due to the absorption of UVB by the atmosphere as previously mentioned.

\subsection{Fading of dyed cloths}

Figs. 4 and 5 show the fading characteristics of Blue wool L2, one of American lightfastness standards. The intensity of solar radiation was shown in terms of UVA and UVB in the respective figures although the radiation ranges widely between about $300 \mathrm{~nm}$ and 30 micron. Moreover, fading results under the radiation by artificial fluorescent lamps are also shown comparatively in the figures.

In Fig. 4, the radiant energy is shown on the UVA basis. The radiant energy of about 500 $\mathrm{kJ} / \mathrm{m}^{2}$ causes the eye minimum noticeable color change of $\Delta \mathrm{E} 3$ [16]. Moreover, about 2000 $\mathrm{kJ} / \mathrm{m}^{2}$ resulted in $\Delta \mathrm{E} 7$ which seems to be moderately faded. In this case, the light intensities from both of sun and UVA fluorescent lamp are shown on the abscissa in terms of UVA radiation. Test specimens were exposed to all the wavelengths of sun light in the experiment.

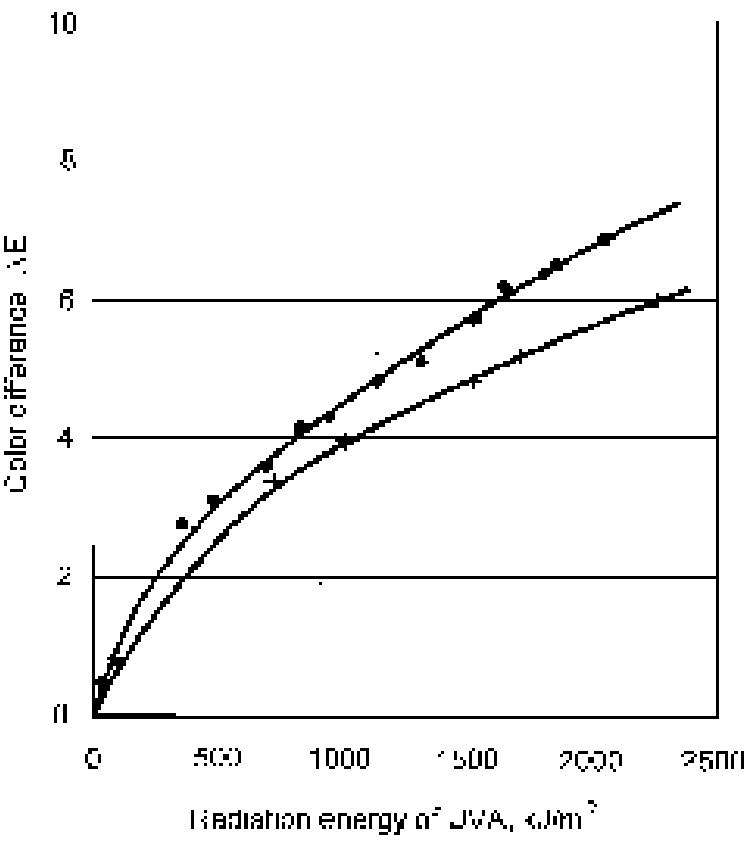

Fig. 4. Fading characteristics of AATCC Blue Wool Lightfastness Standard L2 exposed to solar radiation and UVA fluorescent lamp on the basis of total UVA radiant energy. $\bullet$ : Under the solar radiation. + : Under the radiation of UVA fluorescent lamp.
In other words, the comprehensive fading caused by sun light is evaluated in an index of UVA intensity in Fig. 4.

On the other hand, UVA fluorescent lamp could emit selectively the light in UVA range although it would emit some other light than UVA as noise components. Therefore, the difference between the two characteristic curves in Fig. 4 could be basically ascribed to the effect of sun light component other than UVA, which would be mostly visible light, on the fading. This is an argument under the assumption that both of UVA derived from the sun and UVA fluorescent lamp would be equivalent.

The difference between two curves is considerably smaller in Fig. 4 compared with results with natural dyestuffs shown later in this paper. The fading effect due to visible light must be relatively small as mentioned earlier.

Fig. 5 shows the fading characteristics of L2 on the basis of UVB radiation, similarly to Fig. 4. It is observed that the radiant energy of about 6 and $40 \mathrm{~kJ} / \mathrm{m}^{2}$ from the sun resulted in color.

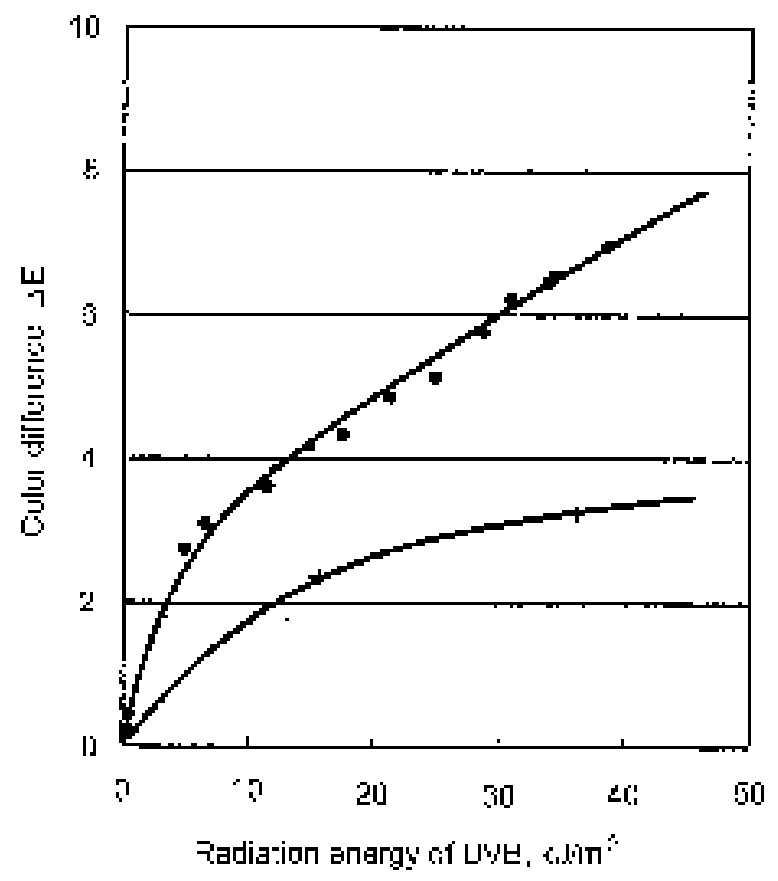

Fig. 5. Fading characteristics of AATCC Blue Wool Lightfastness Standard L2 exposed to solar radiation and UVB fluorescent lamp on the basis of total UVB radiant energy. •: Under the solar radiation. + : Under the radiation of UVB fluorescent lamp. 
changes of $\Delta \mathrm{E} 3$ and 7 , respectively The difference between the two curves is fairly large. It seems that UVB radiation could explain only about half the fading of L2 under sun light. The difference between the two curves is ascribed to components in the solar radiation other than UVB radiation, for example, UVA radiation and visible light.

In conclusion, most of the fading of AATCC Lightfastness Standard L2 under solar radiation could be attributed to UVA and UVB radiation; the effect of visible light appears to be very small. This observation is consistent with previous findings by Crews [6], who reported that AATCC Blue Wool L2 is not as sensitive to visible light as most natural dyes included in her study of the effectiveness of UV filtering materials in reducing fading of museum artifacts.

It is generally accepted that the energy per photon is higher as wavelength gets lower and UVB is more effective in fading than UVA. However, the argument in this paper is based on the actual solar radiation where UVB intensity is less by a factor of about 40 than UVA. Then, the actual effects of UVA and UVB in the solar radiation were discussed as above mentioned.

Figs. 6 and 7 show the fading characteristics of Wool cloth dyed with madder using alum as mordant. The coloring matters in madder are anthraquinones. There are at least 19 anthraquinone components, the most important of which are alizarin and purpurin. Two curves of results are shown simultaneously in the respective figures similarly to previous discussion in Figs. 4 and 5.

Lightfastness of madder seems to be weaker by a factor of about 1.5 than L2, Blue Wool Lightfastness Standard of AATCC in the comparison between Figs. 4 and 6 on the radiant energy basis. Moreover, the difference between the amount of fading caused by sunlight versus the UVA fluorescent lamp is much greater for madder than for L2 (see Fig. 6 versus Fig. 4). Exposure to UVA radiation could explain about two thirds of the fading behavior. UVB radiation seems to explain about one fourth of the fading (see Fig. 7). These results suggest that the effect of visible light is fairly large on the fading of madder. In other words, madder is more sensitive to visible light than AA TCC Blue Wool L2.

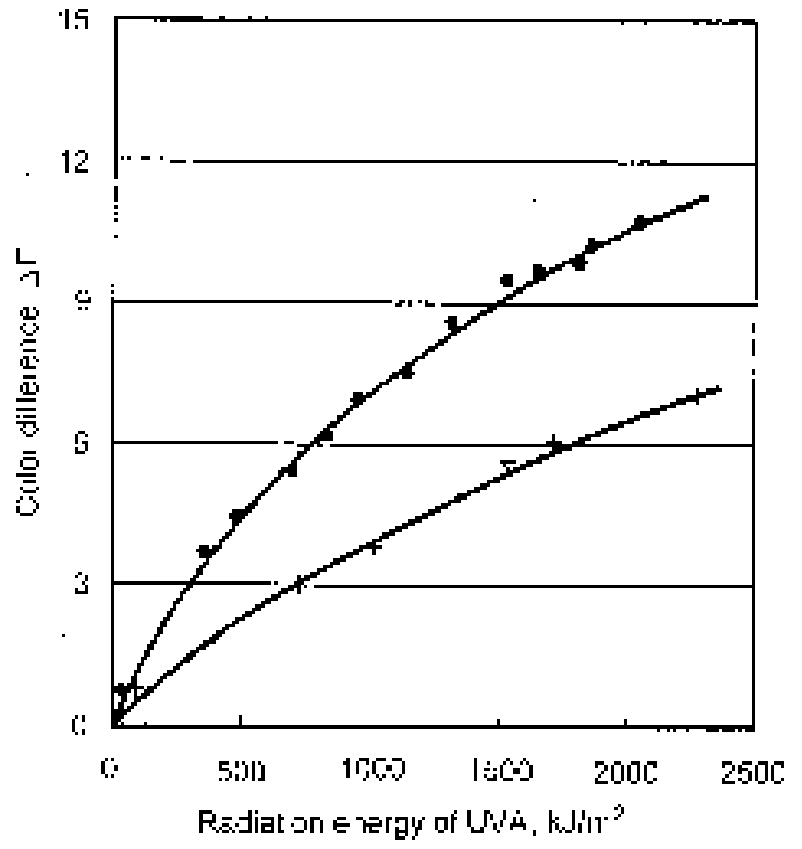

Fig. 6. Fading characteristics of wool cloth dyed with madder exposed to solar radiation and UVA fluorescent lamp on the basis of total UVA radiant energy. $\bullet$ : Under the solar radiation. + : Under the radiation of UVA fluorescent lamp.

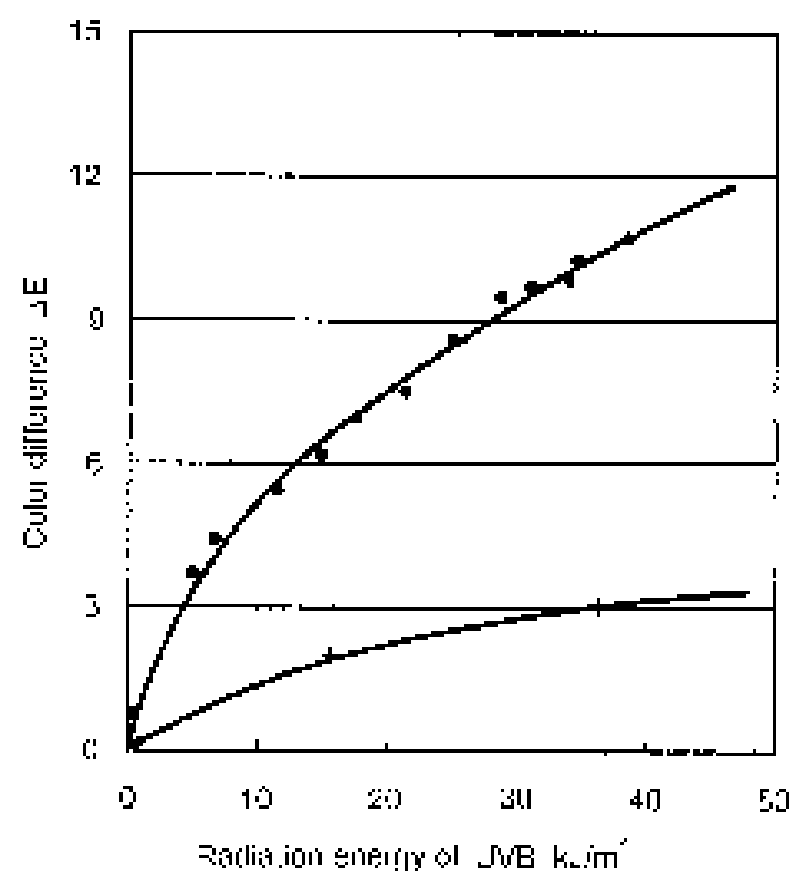

Fig. 7. Fading characteristics of wool cloth dyed with madder exposed to solar radiation and UVB fluorescent lamp on the basis of total UVB radiant energy. $\bullet$ : Under the solar radiation. + : Under the radiation of UVB fluorescent lamp. 


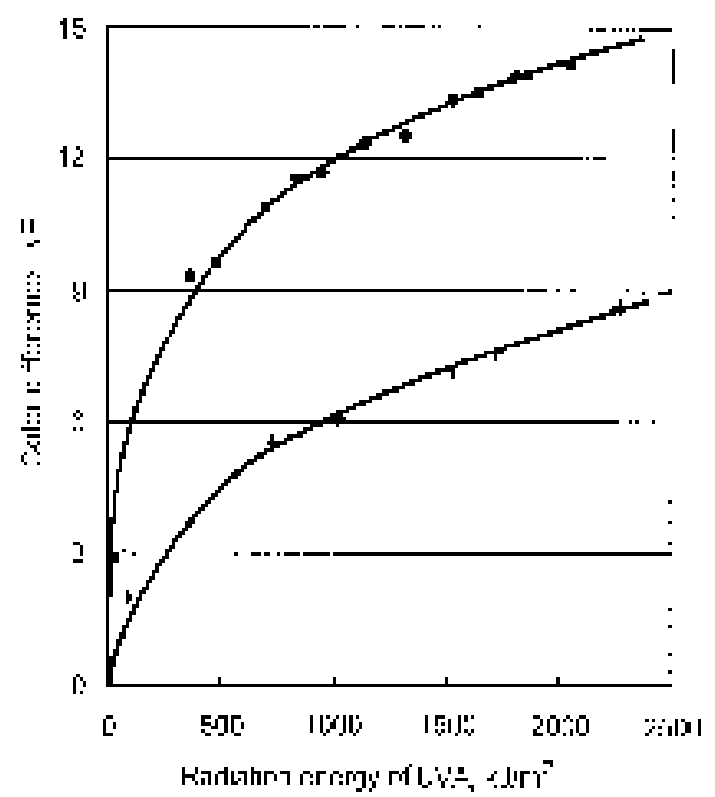

Fig. 8. Fading characteristics of wool cloth dyed with weld exposed to solar radiation and UVA fluorescent lamp on the basis of total UVA radiant energy. •: Under the solar radiation. + : Under the radiation of UVA fluorescent lamp.

Figs. 8 and 9 show the fading characteristics of wool cloth dyed with weld using alum as mordant. The coloring compounds in weld are luteolin and apigenin, both of which are flavones. Weld seems to be less lightfast by a factor of about 2 than AATCC Blue Wool L2 in the comparison between Figs. 4 and 8 on the radiant energy basis.

The difference between the characteristic curves of weld compared to L2 is very large (see Fig. 8 compared with Fig. 4). Exposure to UVA radiation could explain the fading behavior by a factor of about three fifths in weld. This result suggests that the effect of visible light on fading of weld is very large. In other words, weld is very sensitive to visible light. As shown in Fig. 9, exposure to UVB radiation can explain the fading to a very small extent, that is, by a factor of one fifth. The results in Figs. 8 and 9 show that visible light contributes greatly to the fading of weld. This susceptibility to fading by visible light, as well as both UV radiation, explains, in part, the poor lightfastness of some natural dyestuffs.

Figs. 10 and 11 show the fading characteristics of wool cloth dyed with turmeric using alum as

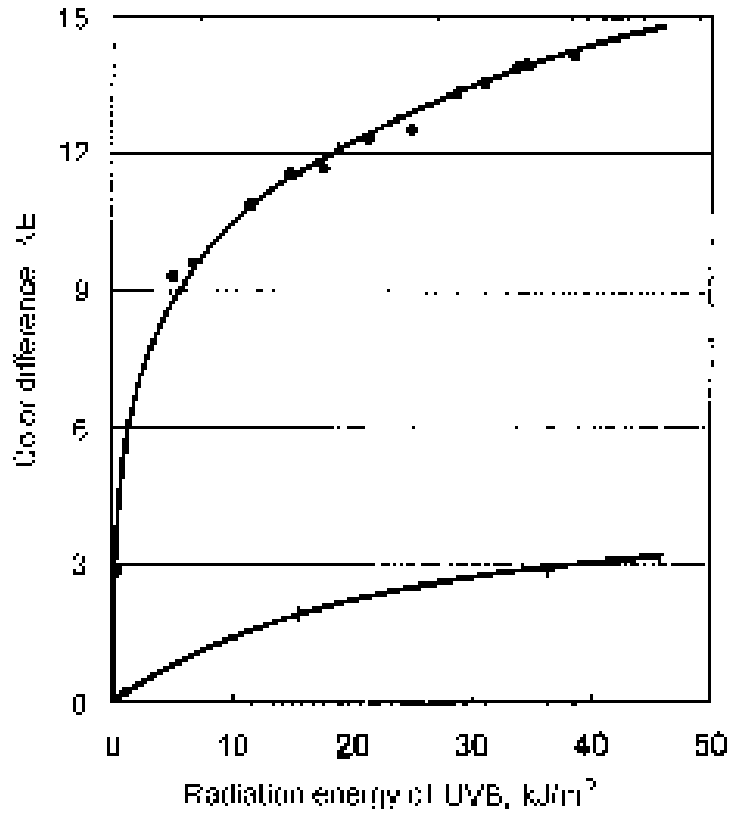

Fig. 9. Fading characteristics of wool cloth dyed with weld exposed to solar radiation and UVB fluorescent lamp on the basis of total UVB radiant energy. $\bullet$ : Under the solar radiation. + : Under the radiation of UVB fluorescent lamp.

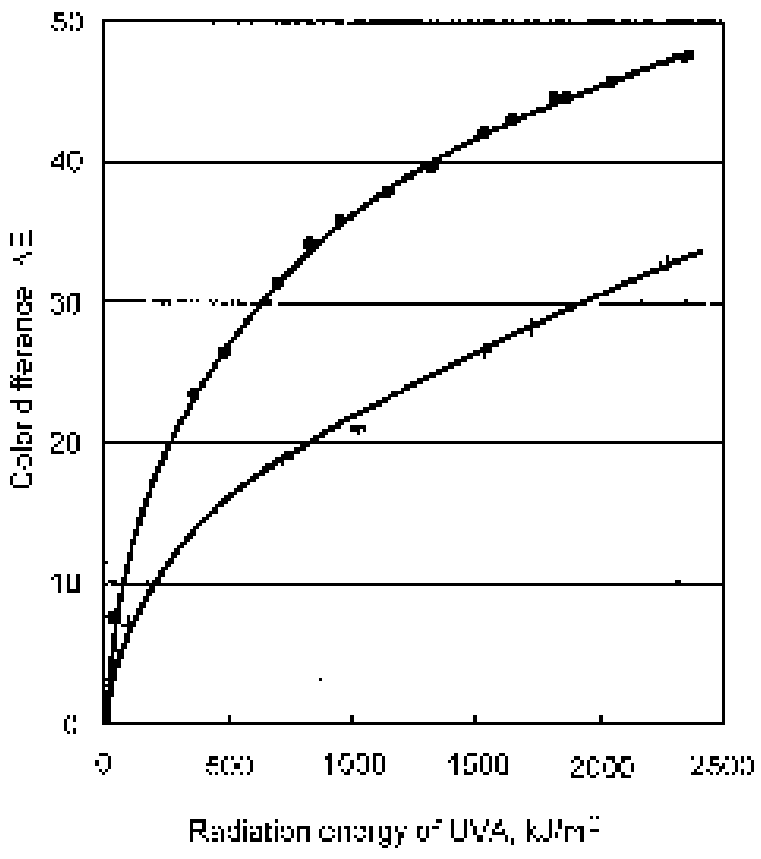

Fig. 10. Fading characteristics of wool cloth dyed with turmeric exposed to solar radiation arid UVA fluorescent lamp on the basis of total UVA radiant energy. $\bullet$ : Under the solar radiation. + : Under the radiation of UVA fluorescent lamp. 


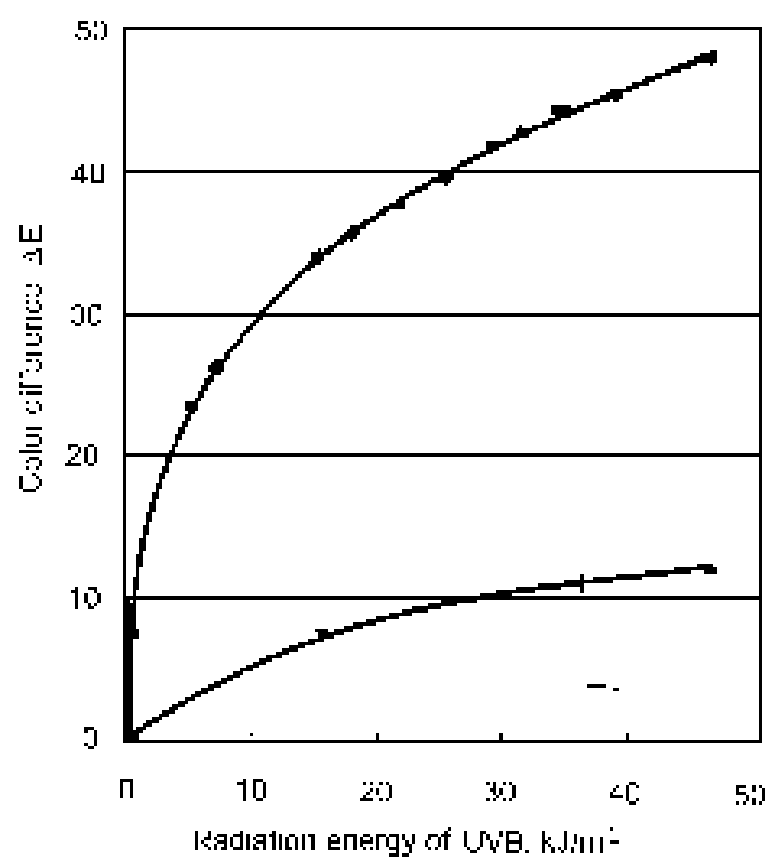

Fig. 11. Fading characteristics of wool cloth dyed with turmeric exposed to solar radiation and UVB fluorescent lamp on the basis of total UVB radiant energy. $\bullet$ : Under the solar radiation. + : Under the radiation of UVB fluorescent lamp.

mordant. The coloring matter in turmeric is curcumin which is classified as an hydroxyketone. Lightfastness of turmeric is considered to have the worst lightfastness among the dyestuffs examined in this study. It is seven times weaker than L2 of AATCC in the comparison between Fig. 4 and Fig. 11 on the radiant energy basis.

UVA radiation seems to explain two thirds of the fading of turmeric as shown in Fig. 10. Visible light also has a fairly strong influence on the fading of turmeric, although the influential ratio of visible light is smaller compared with weld. UVB radiation does not contribute to fading of turmeric as much as UVA radiation does. Based on these results, fading in turmeric may be attributed primarily to UVA radiation, however visible light and UVB radiation are also influential.

\section{Conclusion}

Fading characteristics of selected natural dye-stuffs were examined under solar radiation from the standpoint of the radiant energy basis. They were observed to have poorer lightfastness than AATCC Blue Wool L2. The order of fading susceptibility to solar radiation is as follows:

Turmeric $>$ weld $>$ madder $>$ L2.

Moreover, UVA and UVB light sources are applied to investigate the fading characteristics of dyed wool cloths. As a result, their respective fading dependencies on wavelength of radiation were found. Results were consistent to earlier studies $[5,6]$ in showing that visible light, as well as UV radiation contribute to fading of some natural dyestuffs. This research, in addition, showed the relative contributions of UVA and UVB in solar radiation to fading of selected natural dyes. UVA radiation was observed to contribute more to fading of natural dyes than UVB radiation in the case of actual solar radiation. These results provide an important key to understanding the poor lightfastness of some natural dyestuffs and the importance of reducing visible light and UVA radiation, as well as UVB radiation, when exposing artifacts to light during museum exhibitions and other consumer uses.

\section{Acknowledgements}

This research was supported in part by the University of Nebraska Agricultural Research Division, Lincoln, NE 68583. Journal Series No.13952.

\section{References}

[1] Padfield T, Landi S. The lightfastness of the natural dyes. Studies in Conservation 1966;11:18195.

[2] Crews PC. The influence of mordant on the lightfastness of yellow natural dyes. J American Institute for Conservation 1982;21:43-58.

[3] Thomson G. The museum environment. 3rd rev ed. London: Butterworth; 1986.

[4] Crews PC. The fading rates of some natural dyes. Studies in Conservation 1987;32:65-72.

[5] Crews PC. A comparison of clear versus yellow ultraviolet filters in reducing fading of selected dyes. Studies in Conservation 1988;33:87-93. 
[6] Crews PC. A comparison of selected UV filtering material for the reduction of fading. J American Institute for Conservation 1989;28;117-25.

[7] Giles CH, McKay RB. The lightfastness of dyes: a review. Textile Res J 1963;33:528-75.

[8] Freeman HS, Hsu WN. Photolytic behavior of some popular disperse dyes on polyester and nylon subatrates. Textile Res J 1987;57:223-34.

[9] Wang YP, Wang IJ. Photolytic behavior of some azo pyridone disperse dyes no polyester substrates. Textile Res J 1992;62(1):15-20.

[10] Katsuda N, Yabushita S, Otake K, Omura T, Takagishi T. Photodegradation of a disperse dye on polyester fiber and in solution. Dyes and Pigments 1996;31:294-300.

[11] Katsuda N, Omura T, Takagishi T. Photodegradation of an anthraquinone type disperse dye on polyester, diacetate, and triacette fibers and in solution. Dyes and Pigments 1997;34:147-57.

[12] Himeno K, Okada Y, Morita Z. Photofading of monoazo disperse dyes on polyester and polyamide substrates. Dyes and Pigments 2000;45:109-23..

[13] Collins S, Davidson RS. Aspects of the photobleaching and photoyellowing of wool. J Soc Dyers Colour 1993; 109:202-9.

[14] Auer PD, Palthorpe MT. Effect of tropical applications of antioxidants and quenchers on the photoyellowing of fluorescently whitened wool fabric. Textile Res J 1995;65(5): 287-93.

[15] Hummel JJ. The dyeing of textile fabric. London: Cassell; 1888.

[16] AATCC evaluation procedure 1: gray scale for color change. AATCC Technical Manual. 2000.

This authors' post-refereed version of the article has been updated to follow the layout and pagination of the original journal publication in Dyes and Pigments 58. 